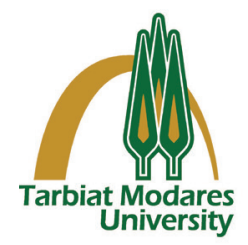

\title{
Risk Factors of Tuberculosis Treatment Failure among Tuberculosis Patients in Khuzestan Province: A Retrospective Cohort Study
}

\section{A R T I C L E I N F O}

Article Type

Original Research

Authors

Sayed Ali Mousavi, $M S c^{1^{*}}$

Mohammad Fararouei, $P h D^{2}$

Hadi Rashidi, $M S c^{3}$

Saeideh Shojaei, $M S c^{4}$

Faeze Bahrami Astaraki, $B S c^{5}$

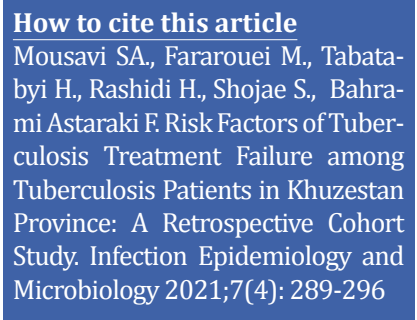

${ }^{1}$ Department of Public Health, Shoushtar Faculty of Medical Science, Shoushtar, Iran ${ }^{2}$ HIV/AIDS Research Center, Shiraz University of Medical Science ${ }^{3}$ Department of Epidemiology, Shiraz University of Medical Sciences, Shiraz, Iran

${ }^{4}$ Epidemiology, Department of Epidemiology, School of Health and Safety, Shahid Beheshti University of Medical Sciences, Tehran, Iran. ${ }^{5}$ Undergraduate Student of Nutrition science, Shoushtar University of Medical

\section{* Correspondence}

Address: Department of Public Health, Shoushtar Faculty of Medical Science, Shoushtar, Iran mousavi_a@Shoushtarums.ac.ir

\section{A B S T R A C T}

Background: Tuberculosis (TB) is an infectious and communicable disease and one of the top ten causes of death throughout the world. Monitoring and evaluating TB treatment outcomes provides the required data for taking the necessary measures to control TB. Thus, this study was carried out to find determinants of treatment failure among patients with smear-positive pulmonary TB in Khuzestan province during 2006-2014

Material and Methods: This retrospective cohort study was conducted over a 9-year period in Khuzestan province. Predictors of treatment failure were analyzed using multivariate logistic regression

Findings: Among 5342 patients, the cumulative incidence of unsuccessful TB treatment was $1.85 \%$. More than half of TB patients (59.2\%) enrolled in this study were male, and most of them were living in urban areas $(79.8 \%)$. Significant predictors of treatment failure were age $(p=\cdot 001)$, weight $(p=\cdot 039)$, number of delayed days in diagnosis $(p=\cdot 01)$, isoniazid resistance $(p \leq \cdot 001)$, and number of bacilli in patients' sputum at the beginning of treatment $(p \leq \cdot 001)$. Conclusion: In this study, the rate of successful treatment was quite high; nevertheless, new cases of treatment failure could be prevented with special efforts such as prompt diagnosis and precise follow-up under Direct Observation Treatment Short course (DOTS) strategy.

Keywords: Tuberculosis, Treatment failure, DOTS, Khuzestan.

\section{CITATION LINKS}

[1] World Health Organization. Global Tuberculosis... [2] World Health Organization, Global Tuberculosis... [3] Tola A, Minshore KM, Ayele Y, Mekuria NA. Tuberculosis... [4] Biruk M, Yimam B, Abrha H, Biruk S, Amdie FZ. Treatment outcomes of tuberculosis and... [5] Jasmer RM, Seaman CB, Gonzalez LC, Kawamura LM, Osmond DH, Daley CL.Tuberculosis treatment... [6] Sharma SK, Kumar S, Saha P, George N, Arora S, Gupta D, et al. Prevalence... [7] World Health Organization. Global... [8] Abassi A, Aarabi M. The efficacy of DOTS strategy in... [9] Endris M, Moges F, Belyhun Y, Woldehana E, Esmael A, Unakal C. Treatment outcome of 4. tuberculosis patients at... [10] Rahimi BA, Rahimy N, Mukaka M, Ahmadi Q, Hayat MS, Wasiq AW. Determinants of treatment failure among... [11] Ministry of Health of Iran. National Center for Tuberculosis and Leprosy Control web... [12] Talay F, Kumbetli S, Altin S. Factors associated... [13] Wen Y, Zhang Z, Li X, Xia D, Ma J, Dong Y, et al. Treatment outcomes and... [14] Melese A, Zeleke B, Ewnete B. Treatment outcome and associated factors among tuberculosis patients in... [15] Pradipta IS, van't Boveneind-Vrubleuskaya N, Akkerman OW, Alffenaar JW, Hak E. Predictors for treatment outcomes among... [16] El-Shabrawy M, El-Shafei DA. Evaluation of treatment failure outcome and its predictors among pulmonary tuberculosis... [17] Umeokonkwoa CD, Okedo-Alex IN, Azuogu BN, Utulua R, Adeke AS, Disub YO. Trend and determinants of tuberculosis treatment... [18] Mohammed T, Daniel K, Helamo D, Leta T. Treatment outcomes of tuberculosis patients in... [19] Muture BN, Keraka MN, Kimuu PK, Kabiru EW, Ombeka VO, Oguya F. Factors associated with default from... [20] Mohammadzadeh K, Ghayoomi A, Maghsoudloo D. Evaluation of... [21] Adeneh HA, Motamedi B, Veisi M, Bagheri S. Risk factors of tuberculosis treatment failure in... [22] Ni W, Yan MA, Liu YH, Jian DU, Zhang H, Xie SH, et al. Risk of treatment failure in patients with drug-susceptible pulmonary... [23] Sharma B. Community contribution to... [24] Mohan A, Nassir H, Niazi A. Does routine... [25] Farazi AA, Jabbari Almasi M, Soufian M. [The effect of... [26] Htun YM, Khaing TMM, Aung NM, Yin Y, Myint Z, Aung ST, et al. Delay in ... [27] Helbling P, Altpeter E, Egger J-M, Zellweger J-P. Treatment...[28] Ministry of Health of Iran. National Center for Tuberculosis and Leprosy Control web site; 2017 [cited 2019]; Available from: http://tb-lep.behdasht. gov.ir/TB_HIV_Situation_in_Iran.aspx. [29] Farazi AA, Jabbari Almasi M, Soufian M. The effect of intencity of sputum smear positive pulmonary tuberculosis patients on treatment response. Med Coun Islamic Rep J 2011; 29:150-6.

\section{Article History}

Received: July 052021

Accepted: September 25,2021

Published: November 25,2021

Copyright(C) 2021, TMU Press. This open-access article is published under the terms of the Creative Commons Attribution-NonCommercial 4.0 International License which permits Share (copy and redistribute the material in any medium or format) and Adapt (remix, transform, and build upon the material) under the Attribution-NonCommercial terms. 


\section{Introduction}

Tuberculosis (TB) is an infectious and communicable disease and one of the top ten causes of death throughout the world. It is the leading cause of death from a single infectious agent, it ranks even higher than HIV/AIDS ${ }^{[1]}$. According to the Global Tuberculosis Report 2018, about 10 million people were infected with $\mathrm{TB}$, of whom 1.3 million and 330 thousand deaths were related to HIV-negative and HIV-positive patients, respectively ${ }^{[2]}$. About $97 \%$ of reported tuberculosis cases are in lowand middle-income countries; thus, these countries are most affected by this disease [2]. Despite proper strategies and management in TB control and the reduction in TB incidence in recent years, more strategies are needed to control the diseaseDespite proper programs and management in tuberculosis control and reducing the incidence of tuberculosis in recent years, more measures are needed to control the disease.

The programs and sound management in TB control and reduce the incidence of TB in recent years, the need for additional measures to control the disease.

${ }^{[3]}$. Based on the Global Tuberculosis Report 2019 , targets set in the end TB plan by 2030 and 2035 are a 90 and 95\% reduction in TB mortality, and a 80 and $90 \%$ reduction in TB incidence compared to levels in 2015, respectively. TB treatment prevented 48 million deaths among HIV-negative people between 2000 and $2018^{[1]}$. The mortality rate due to non-treated TB is high. Some studies have shown that according to the natural history of TB, only in 30\% of sputum smearpositive pulmonary TB cases, According to the history of tuberculosis, tuberculosis does not lead to death in only $30 \%$ of cases without the use of anti-tuberculosis drugs. Based on the history of tuberculosis, tuberculosis without the use of anti-TB drugs in only $30 \%$ of cases are not fatal. tuberculosis does not lead to death within 10 years after diagnosis without the use of anti-tuberculosis drugs ${ }^{[2]}$. TB should be treated for at least 6 months. The first line of TB treatment is at least 6 months.

During this period, drugs (rifampicin, isoniazid, ethambutol, and pyrazinamide) are used During this period, drugs (rifampicin, isoniazid, ethambutol and pyrazinamide) are used.

In the course of drugs (rifampicin, isoniazid, ethambutol and pyrazinamide) is used under direct observation ${ }^{[4-5]}$. Inadequate treatment could lead to the emergence of strains resistant to treatment, and this has been a serious alarm for the TB control strategy in recent decades [6]. Monitoring and evaluating TB treatment outcomes, especially in health centers, provides useful and usable information about the effectiveness of the control plan ${ }^{[7]}$. Many studies have revealed a significant relationship between Direct Observation Treatment Short course (DOTS) strategy and treatment failure index ${ }^{[8]}$. In a study in Ethiopia, known risk factors for treatment failure were listed as follows: age over 55 years, male gender, re-treatment, and distance to treatment center ${ }^{[9]}$. In another study in Afghanistan, determinants that may cause treatment failure were shown to be re-treatment, absence of fever, absence of cough, living in rural areas, and no weight loss ${ }^{[10] .}$

Treatment outcome is one of the best measures to explain how current TB regimens work ${ }^{[10]}$. Khuzestan is in the third place of TB infection after Sistan and Baluchistan and Golestan provinces [11]. Objectives: This study was carried out to find factors associated with treatment failure among patients with smear-positive pulmonary TB in Khuzestan province during 2006-2014. 


\section{Materials and Methods}

This retrospective cohort study was conducted to identify determinants of TB treatment failure and associated risk factors. Data were collected from 5342 TB patients diagnosed with routine methods and registered at the center for TB disease in Khuzestan province from 2006 to 2014. Demographic data, such as age, sex, place of residence, clinical data, HIV status, and other related information, were collected in the registration forms. Inclusion criteria were as follows: patients with smear-positive pulmonary TB and patients whose sputum smear tests were negative but changed to positive during treatment.

Patient whose sputum smear was TB negative before and after the beginning of treatment were excluded from the study. Treatment failure was determined by the criteria of Iranian National Guideline for the Control of Tuberculosis as follows: all new smear-positive patients whose smear results were also positive at the end of the fifth month of treatment or all patients whose sputum smear was negative but turned to positive at any stage of treatment. For ethical aspects, patients' names were replaced by numbers. To improve reliability, data were collected from both standardized paper-based treatment cards and electronic records and verified during data collection, entry, and analysis processes. After data collection, they were cleaned and analyzed using SPSS statistics package Version 19. The distribution of participants' characteristics and cumulative incidences were examined using descriptive statistics.

\section{Findings}

During a 9-year period, a total of 5342 patients were treated in public health facilities. The cumulative incidence of unsuccessful TB treatment was 1.85\% (99 of 5342). More than half of TB patients
(59.2\%) were male, and the male to female ratio was 1.5 to 1 . Most patients were living in urban areas (79.8\%). A total of 158 patients $(12.9 \%$ of tested patients) were HIV co-infected. Among whom, 8.2\% had EPTB (extrapulmonary TB), and 8.3\% had a history of prison (Table 1).

The univariate analysis results showed that treatment outcome was significantly $(p<.05)$ associated with age $(p=\cdot 001)$, weight $(p=$ .039), number of delayed days in diagnosis $(p=\cdot 01)$, isoniazid resistance $(p \leq \cdot 001)$, and number of bacilli in patients' sputum at the beginning of treatment $(p \leq \cdot 001)$. The treatment outcomes and treatment failure predictors are shown in Table 2 .

In multivariate logistic regression, age, delay in diagnosis, misdiagnosis, and number of bacilli in patients' sputum at the beginning of treatment were found to be independently and significantly associated with treatment failure. The two variables of gender ( $p=$ .052) and weight ( $p=\cdot 085$ ) had a significant impact only on the univariate model. Table 3 shows the analysis results of factors affecting treatment outcomes.

\section{Discussion}

TB is a major public health problem worldwide, especially in developing counrties. Monitoring TB treatment outcomes is a way to evaluate the performance and effectiveness of treatment strategies such as DOTS. This retrospective study aimed to assess TB treatment outcomes and associated factors. Treatment failure is a major problem in TB control. In this study, the cumulative incidence of treatment failure was 1.85\%. Almost similar results have been reported in other studies conducted in different parts of the world, including Turkey $(0.3 \%){ }^{[12]}$, China $(0.5 \%)^{[13]}$, Ethiopia (1.2 and 3.5\%) ${ }^{[3,14]}$, and Netherland $(2.6 \%){ }^{[15]}$. Most patients in this study were male, which is compatible with other studies conducted worldwide ${ }^{[16-18]}$, this 
could be due to the fact that men are more likely to be infected in the community and use health facilities than women. The present study findings showed that treatment failrure is $50 \%$ more likely to occur in men than in women, and that male gender is an important predictor of treatment failure, which is in agreement with other studies results [19-20]. In a previous study, male gender was not identified as a risk factor for treatment failure, which may be due to insufficient sample size [21]. The present study showed that the risk of treatment failure significantly increased with increasing patients' age, which is consistent with the findings of other studies [13, 16-17, 22], indicating that younger patients had a higher rate of treatment success. This could be attributed to the weakened immune system in the elderly, the cumulative effects of tobacco consumption, or air pollution, which were not addressed in this study. In a similar study conducted on 52 patients in another part of Iran with the same subject, no significant relationship was found between age and treatment failure, which could be ascribed to the discrepancy in the sample size of these two studies ${ }^{[16]}$. Another variable identified as a risk factor for unsuccessful TB treatment was misdiagnosis of patients. This is a new term specific to the current study and refers to cases who are simutaneously infected with both pulmonary and nonpulmonary TB and incorrectly classified into non-pulmonary group; thus, DOTS strategy is not used for them. Misdiagnosis increases the risk of treatment failure by indirectly affecting DOTS function, as the risk of treatment failure in misdiagnosed cases is $41 \%(\mathrm{RR}=1.41)$. The results of other studies by Abbasi [8], Sharma [23], and Mohan [24] support our finding. Given that the DOTS strategy is only applicable to smear-positive pulmonary TB patients, those pulmonary patients who are incorrectly classified into non-pulmonary group receive no direct monitoring, justifying the relationship between misdiagnosis and

Table 1) Demographic characteristics of patients with tuberculosis in Khuzestan province during 2006-2014

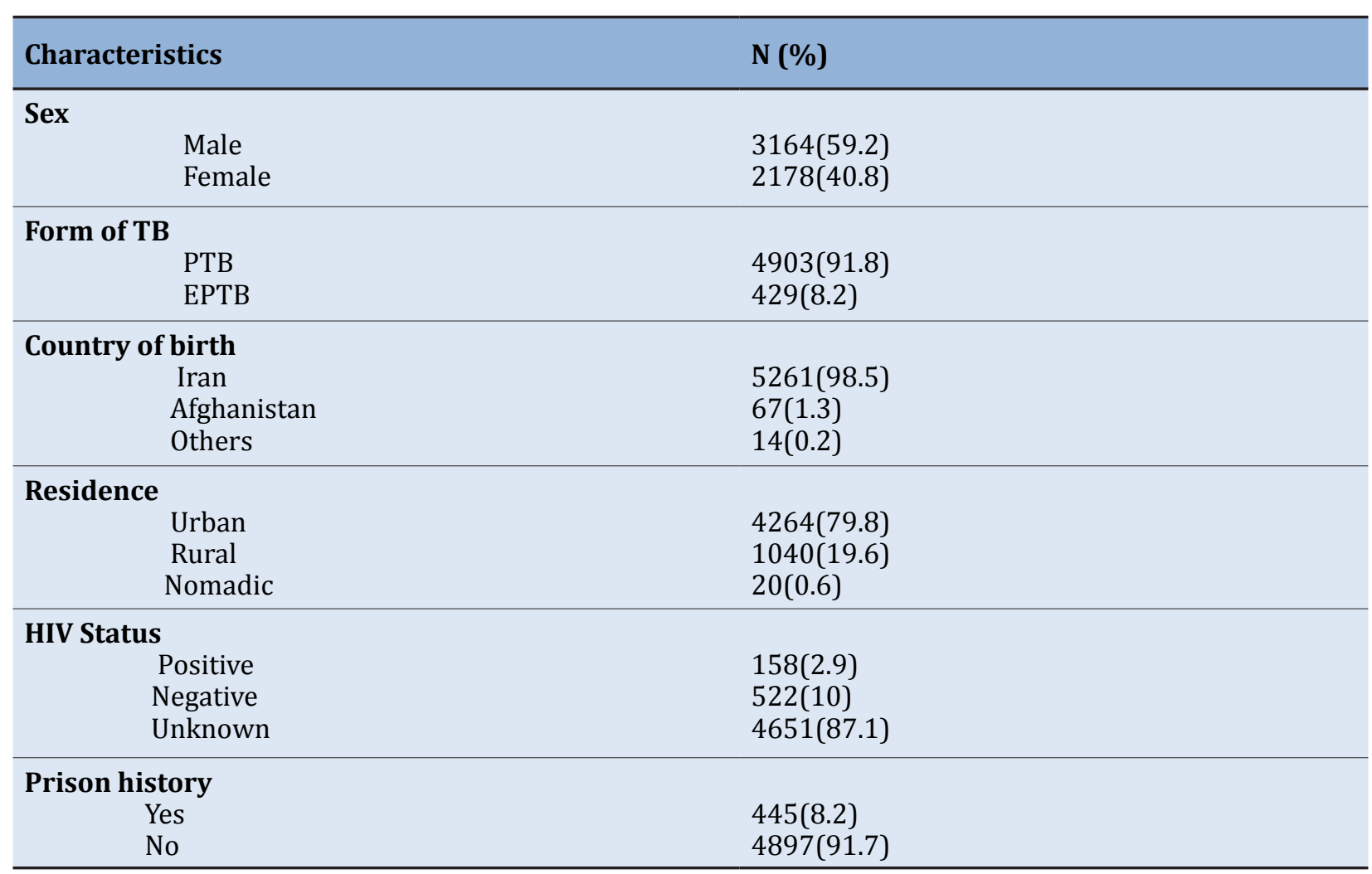


Table 2) Univariate analysis of factors associated with treatment failure in patients with Tuberculosis in Khuzestan province

\begin{tabular}{|c|c|c|c|c|}
\hline \multirow[b]{2}{*}{ Characteristics } & \multicolumn{2}{|c|}{ Treatment Outcome } & \multirow[b]{2}{*}{$\begin{array}{c}\text { Relative } \\
\text { Risk }\end{array}$} & \multirow[b]{2}{*}{ P-Value } \\
\hline & $\underset{\mathbf{N}}{\text { Successful }}$ & $\underset{\mathbf{N}}{\text { Failed }}$ & & \\
\hline \multicolumn{5}{|l|}{ Sex } \\
\hline Male & 3096 & 68 & 1.50 & .06 \\
\hline Female & 2147 & 31 & & .06 \\
\hline \multicolumn{5}{|l|}{ Country of birth ${ }^{1}$} \\
\hline Iran & 5162 & 99 & $*$ & .4 \\
\hline Non-Iran & 81 & 0 & & \\
\hline \multicolumn{5}{|l|}{ Residence } \\
\hline Urban & 4183 & 81 & 1.12 & 69 \\
\hline Rural \& nomadic & 1060 & 18 & & .09 \\
\hline \multicolumn{5}{|l|}{ HIV status } \\
\hline Positive & 156 & 2 & 0.76 & \\
\hline Negative & 524 & 9 & & 1.00 \\
\hline \multicolumn{5}{|l|}{ Prison history } \\
\hline Yes & 438 & 7 & 0.84 & 85 \\
\hline No & 4805 & 92 & & .0J \\
\hline \multicolumn{5}{|l|}{ Chest radiography ${ }^{2}$} \\
\hline Rejected TB & 118 & 0 & $*$ & \\
\hline Suspected TB & 451 & 5 & s & .17 \\
\hline Confirmed TB & 1594 & 31 & & \\
\hline \multicolumn{5}{|l|}{ History of TB contact } \\
\hline Yes & 555 & 14 & 1.14 & .63 \\
\hline No & 1894 & 42 & & \\
\hline \multicolumn{5}{|l|}{ Drug side-effect } \\
\hline Yes & 88 & 2 & 2.75 & .68 \\
\hline No & 5155 & 97 & & \\
\hline \multicolumn{5}{|l|}{$\begin{array}{l}\text { Sputum smear at the } \\
\text { beginning of treatment }\end{array}$} \\
\hline $1-9$ bacilli & - & 17 & $*$ & \\
\hline+ & - & 4 & $*$ & .0001 \\
\hline++ & 788 & 12 & & \\
\hline+++ & 1738 & 47 & & \\
\hline \multicolumn{5}{|l|}{ Imported case } \\
\hline Yes & 46 & - & $*$ & 1 \\
\hline No & 5197 & 99 & & \\
\hline \multicolumn{5}{|l|}{ Recurrence } \\
\hline Yes & 105 & - & $*$ & .26 \\
\hline No & 5138 & 99 & & \\
\hline \multicolumn{5}{|l|}{ Absence of treatment } \\
\hline Yes & 165 & 4 & 1.33 & .55 \\
\hline No & 5077 & 95 & & \\
\hline
\end{tabular}


Table 2) Univariate analysis of factors associated with treatment failure in patients with Tuberculosis in Khuzestan province

\begin{tabular}{|c|c|c|c|c|}
\hline \multirow[b]{2}{*}{ Characteristics } & \multicolumn{2}{|c|}{ Treatment Outcome } & \multirow[b]{2}{*}{$\begin{array}{l}\text { Relative } \\
\text { Risk }\end{array}$} & \multirow[b]{2}{*}{ P-Value } \\
\hline & $\begin{array}{l}\text { Successful } \\
\mathbf{N}\end{array}$ & $\begin{array}{c}\text { Failed } \\
\mathbf{N}\end{array}$ & & \\
\hline \multicolumn{5}{|l|}{ Misdiagnosis $^{4}$} \\
\hline Yes & 897 & 22 & 1.41 & .015 \\
\hline No & 4346 & 77 & & \\
\hline \multicolumn{5}{|l|}{ Isoniazid resistance } \\
\hline Yes & 10 & 1 & 5.55 & .001 \\
\hline No & 5230 & 97 & & \\
\hline Mean \pm SD & $39 \pm 18$ & $45 \pm 18$ & $* *$ & .001 \\
\hline $\begin{array}{l}\text { Weight (kg) } \\
\quad \text { Mean } \pm \text { SD }\end{array}$ & $55 \pm 12 \cdot 4$ & $53 \pm 12$ & $* *$ & .039 \\
\hline $\begin{array}{l}\text { Delay in treatment (day) } \\
\text { Mean } \pm \text { SD }\end{array}$ & $5 \cdot 9 \pm 24$ & $4 \cdot 4 \pm 7 \cdot 8$ & $* *$ & $\cdot 08$ \\
\hline $\begin{array}{c}\text { Delay in diagnosis (day) } \\
\text { Mean } \pm \text { SD }\end{array}$ & $79 \pm 100$ & $104 \pm 125$ & $* *$ & $\cdot 011$ \\
\hline
\end{tabular}

1. Fisher test

2. +: 10-99 bacilli per 100 microscope high-power fields

$++:$ 1-10 bacilli per microscope high-power field

+++ : more than 10 bacilli per microscope high-power field

3. Combined for testing rejected and suspected groups

4. People who were diagnosed as EPTB despite a positive sputum smear.

* Not calculable

** Not applicable

Table 3) Final model of multivariate analysis of factors related to treatment failure in tuberculosis patients in Khuzestan province

\begin{tabular}{lccc}
\hline Characteristics & Coefficient B & Odds Ratio (CI95\%) & P=Value \\
\hline Age & 0.01 & $1.01(1-1.02)$ & .001 \\
\hline Sex (male) & 0.44 & $1.57(0.99-2.46)$ & .052 \\
\hline Weight & 0.016 & $0.98(0.96-1.0022)$ & .085 \\
\hline Delay in diagnosis (day) & 0.02 & $1.0016(1.00061-1.0031)$ & .042 \\
\hline Misdiagnosis (yes) & 0.63 & $1.87(1.16-3.030)$ & .0097 \\
\hline $\begin{array}{l}\text { Smear positive after } \\
\text { treatment +++ }\end{array}$ & 0.89 & $2.18(1.26-3.80)$ & .0054 \\
\hline
\end{tabular}

treatment failure. According to the results, TB treatment outcomes are significantly affected by the degree of smear positivity at the beginning of treatment; the more positive the smear is, the lower the treatment success index, this finding is consistent with the finding of another study by Farazi and colleagues (2010) ${ }^{[25]}$. Delay is an important index in TB treatment, which could be defined as delay in diagnosis and delay in treatment. This study results showed an association between the risk of treatment failure and delay in diagnosis. A study conducted in China reported that there is an inverse relationship 
between treatment success and delay in diagnosis, so that as the delay increases, the treatment success rate decreases ${ }^{[13]}$. Delay in treatment was not identified as a risk factor in this study; this finding is in line with the findings of other studies conducted in Myanmar and Switzerland [26-27]. Therefore, longer delays in treatment are likely to lead to poorer treatment outcomes; however, more studies are needed to investigate the impact of this risk factor on treatment outcomes.

\section{Conclusion}

According to the results, accurate diagnosis of smear-positive pulmonary tuberculosis, timely treatment, and the use of DOTS strategy could prevent new cases of treatment failure. It is recommended that future studies evaluate the role of other variables such as the number of days DOTS is performed, smoking history, and smoking duration.

\section{Aknowledgement}

We would like to thank you the Jundishapor university of medical science for providing the data.

Ethical Permission: The ethical code of the present study was obtained from the Shiraz University of Medical Sciences Ethics Committee (IR.SUMS.REC.1393.S7301).

Conflict of Interests: No potential conflict of interest relevant to this article was reported.

Authors' Contribution: Conceptualization: SAM; Data collection and laboratory analysis: SS, FBA; Interpretation of the results: SAM, MF, HT; Writing of original draft: SAM, HR; Writing, reviewing and editing: SAM, MF. All authors read and approved the manuscript. Fundings: This research is a part of the Master's thesis on Epidemiology, which was performed by financial support of Shiraz University of Medical Sciences.

Consent to participate: Verbal informed consent to participate were obtained from individual participants during data collection and after official corresponding with Jundishapour university of medical science, in order to maintain confidentiality, all data were received anonymously.

\section{References}

1. World Health Organization. Global Tuberculosis Report 2019. World Health Organization: 2019.

2. World Health Organization, Global Tuberculosis Report 2018. World Health Organization:2018.

3. Tola A, Minshore KM, Ayele Y, Mekuria NA. Tuberculosis treatment outcomes and associated factors among TB patients attending public hospitals in Harar town, eastern Ethiopia: A five-year retrospective study. Tuberc Res Treat. 2019;2019:1-11.

4. Biruk M, Yimam B, Abrha H, Biruk S, Amdie FZ. Treatment outcomes of tuberculosis and associated factors in an Ethiopian university hospital. Adv Public Health. 2016;2016:1-9.

5. Jasmer RM, Seaman CB, Gonzalez LC, Kawamura LM, Osmond DH, Daley CL.Tuberculosis treatment outcomes directly observed therapy compared withself-administered therapy. Am J Respir Crit Care Med. 2004;170(5):561-6.

6. Sharma SK, Kumar S, Saha P, George N, Arora S, Gupta D, et al. Prevalence of multidrug-resistant tuberculosis among category II pulmonary tuberculosis patients. Indian J Med Res. 2011;133(3):312-5.

7. World Health Organization. Global Tuberculosis Report 2015. World Health Organization; 2015.

8. Abassi A, Aarabi M. The efficacy of DOTS strategy in treatment or failure of treatment in respiratory tuberculosis. J Gorgan Univ Med Sci. 2004;6(13):78-82.

9. Endris M, Moges F, Belyhun Y, Woldehana E, Esmael A, Unakal C. Treatment outcome of 4. tuberculosis patients at Enfraz health center, northwest Ethiopia: A five-year retrospective study. Tuberc Res Treat. 2014;2014:1-7.

10. Rahimi BA, Rahimy N, Mukaka M, Ahmadi Q Hayat MS, Wasiq AW. Determinants of treatment failure among tuberculosis patients in Kandahar city, Afghanistan: A 5 year retrospective cohort study. Int J Mycobacteriol. 2019;8(4):359-65.

11. Ministry of Health of Iran. National Center for Tuberculosis and Leprosy Control web site; 2017 [cited 2019]; Available from: http://tb-lep. behdasht.gov.ir/TB_HIV_Situation_in_Iran.aspx

12. Talay F, Kumbetli S, Altin S. Factors associated with treatment success for tuberculosis patients: A single center's experience in Turkey. Jpn J Infect Dis. 2008;61(1):25-30.

13. Wen Y, Zhang Z, Li X, Xia D, Ma J, Dong Y, et 
al. Treatment outcomes and factors affecting unsuccessful outcome among new pulmonary smear positive and negative tuberculosis patients in Anqing, China: A retrospective study. BMC Infect Dis. 2018;18(1):1-2.

14. Melese A, Zeleke B, Ewnete B. Treatment outcome and associated factors among tuberculosis patients in Debre tabor, northwestern Ethiopia: A retrospective study. Tuberc Res Treat. 2016;2016.

15. Pradipta IS, van't Boveneind-Vrubleuskaya N, Akkerman OW, Alffenaar JW, Hak E. Predictors for treatment outcomes among patients with drugsusceptible tuberculosis in the Netherlands: A retrospective cohort study. Clin Microbiol Iifect. 2019;25(6): 761.e1-e7.

16. El-Shabrawy M, El-Shafei DA. Evaluation of treatment failure outcome and its predictors among pulmonary tuberculosis patients in Sharkia Governorate, 2013-2014. Egypt J Chest Dis Tuberc. 2017;66(1):145-52.

17. Umeokonkwoa CD, Okedo-Alex IN, Azuogu BN, Utulua R, Adeke AS, Disub YO. Trend and determinants of tuberculosis treatment outcome in a tertiary hospital in southeast Nigeria. J Iinfect Public Health. 2020;13(7):1029-33.

18. Mohammed T, Daniel K, Helamo D, Leta $\mathrm{T}$. Treatment outcomes of tuberculosis patients in nigist Eleni Mohammed general hospital, hosanna, southern nations, nationalities and peoples region, Ethiopia: A five year (June 2009 to August 2014) retrospective study. Arch Public Health. 2017;75(1):1-10.

19. Muture BN, Keraka MN, Kimuu PK, Kabiru EW, Ombeka VO, Oguya F. Factors associated with default from treatment among tuberculosis patients in Nairobi province, Kenya: A case-control study. BMC Public Health. 2011;11(1):1-10.

20. Mohammadzadeh K, Ghayoomi A, Maghsoudloo D. Evaluation of factors associated with failure of tuberculosis treatment under DOTS in northern Islamic Republic of Iran. East Mediterr Health J.
2016;22(2):87-94.

21. Adeneh HA, Motamedi B, Veisi M, Bagheri S. Risk factors of tuberculosis treatment failure in southeast of Iran. J Gordan Univ Med Sci. 2014;16(2):50-6.

22. Ni W, Yan MA, Liu YH, Jian DU, Zhang H, Xie SH, et al. Risk of treatment failure in patients with drugsusceptible pulmonary tuberculosis in China. Biomed Environ Sci. 2016;29(8):612-7.

23. Sharma B. Community contribution to TB care: An Asian perspective. World Health Organization; 2002.

24. Mohan A, Nassir H, Niazi A. Does routine home visiting improve the return rate and outcome of DOTS patients who delay treatment? East Mediterr Health J. 2003;9(4):702-8.

25. Farazi AA, Jabbari Almasi M, Soufian M. [The effect of intencity of sputum smear positive pulmonary tuberculosis patients on treatment response]. Med Coun Islamic Rep J 2011; 29:150-6. (persian)

26. Htun YM, Khaing TMM, Aung NM, Yin Y, Myint Z, Aung ST, et al. Delay in treatment initiation and treatment outcomes among adult patients with multidrug-resistant tuberculosis at Yangon Regional Tuberculosis Centre, Myanmar: A retrospective study. PLoS One. 2018;13(12):e0209932.

27. Helbling P, Altpeter E, Egger J-M, Zellweger J-P. Treatment outcomes of multidrug-resistant tuberculosis in Switzerland. Swiss Med Wkly. 2014;144(4950):w14053.

28. Ministry of Health of Iran. National Center for Tuberculosis and Leprosy Control web site; 2017 [cited 2019]; Available from: http://tb-lep.behdasht. gov.ir/TB_HIV_Situation_in_Iran.aspx

29. Farazi AA, Jabbari Almasi M, Soufian M. [The effect of intencity of sputum smear positive pulmonary tuberculosis patients on treatment response]. Med Coun Islamic Rep J 2011; 29:150-6. (persian) 